\title{
Health marketing in an emerging market: the critical role of signaling theory in breast cancer awareness
}

Judith Fletcher-Brown and Vijay Pereira

University of Portsmouth, Portsmouth Business School, BT1.05 Burnaby Terrace, Burnaby Road, Portsmouth, Hampshire PO1 3AE, United Kingdom

Munyaradzi W. Nyadzayo

University of Wollongong in Dubai, Department of Business and Management, Block 15, Knowledge Park, Dubai, United Arab Emirates

\begin{abstract}
In India, breast cancer is the most commonly diagnosed type of cancer among women in cities and urban areas, yet women seek medical care extremely late due to lack of awareness about self-examination. This study explores the health marketing literature via signaling theory, to uncover the unique social, economic, cultural and institutional challenges and opportunities faced by health marketers and consumers in breast cancer awareness (BCA) in an emerging economy - India. An interpretive-inductive method, alongside a grounded theory approach via focus groups with medical professionals and interviews with women is employed. Findings reveal complex challenges at national, state and community levels which impact negatively on the reputation of India's health sector. Social marketing strategies could be leveraged to raise BCA via community health activists. Propositions are suggested and a conceptual framework is developed to assist health marketers to manage BCA in an emerging economy.
\end{abstract}


Keywords Health marketing; Breast cancer awareness; Signaling theory; India; Emerging economy 


\section{Introduction}

Breast cancer is the most common cancer in most cities in India, including Mumbai, Delhi, Bengaluru, Bhopal, Kolkata, Chennai and Ahmedabad, accounting for $25 \%$ to $32 \%$ of all female cancers (Breast Cancer India, 2016). In India, breast cancer is the most commonly diagnosed type of cancer for urban Indian women (Bawa, 2012; Murthy et al., 2007).

Statistics show that 70,218 Indian women died of breast cancer in 2012 and by 2020 breast cancer is set to overtake cervical cancer as the most common type of cancer among all women in India (Shetty, 2012). In Western countries, breast cancer incidence rates increase with age, unlike India, where the rate of incidence is reversed, with the highest female mortality rate occurring in those aged between 30-50 (Khokhar, 2012). Studies show women seek medical care extremely late due to a lack of awareness about self-examination and India's unique socio-cultural complexity (Rath \& Gandhi, 2014; Shetty, 2012). Thus, women's breast healthcare in India is neglected (Khokhar, 2012). The problem appears to manifest first, from insufficient government investment in developing an effective breast cancer awareness (BCA) strategy and second, the consequences of India's rapid economic development.

Globally, “...most developing countries have pursued formal health care system strategies which give primacy to government roles in financing and delivering health services" (Berman, 1998, p. 1463). However, for India, the task of delivering healthcare to over a billion people has proven a challenging and complex task, especially with the growing middle classes demanding higher quality healthcare services (Brosius, 2012). Healthcare in India is, at present, predominantly the responsibility of the central and state governments, each of the 29 respective states having control over delivering its own health services. However, overall control is held by the Ministry of Health and Family Welfare (hereafter MoHFW). Previous research has documented several challenges within the healthcare 
industry in India, including remuneration, motivation, commitment, quality, productivity, retention and training (e.g., Astor et al., 2005; Martinez \& Martineau, 1998; O’Donnell et al., 2008; Sengupta \& Nundy, 2005; Vujicic et al., 2004). India is also witnessing a growth in the private healthcare sector and evidence indicates that this industry will impact greatly on the economy, similar to the boom in the Information Technology-Business Process Outsourcing (IT-BPO) industry (NASSCOM, 2010). The federal budgets of 2011-16, showed on average a 10-20\% rise in the health budget (federal budget speeches 2011-2016). For example, the funds from 2010-2011 for health rose to \$5.9bn or £3.7bn (BBC, 2011) and in 2017-18 the health budget is expected to get a $\$ 1.5$ billion, or $27 \%$, increase in funding to around $\$ 7$ billion (Kalra, 2016). However, there is no strategic focus on women's breast healthcare (Gangane et al., 2016).

India has grown rapidly over the last decade and is poised to be the fourth largest economy at the end of this decade (Budhwar \& Varma, 2010). The burgeoning economy has enabled the establishment of new business sectors, such as technology and telecommunications, as a result of an influx of foreign direct investments (Budhwar \& Varma, 2010). Such contemporary industries are providing new opportunities for urban working women to benefit from international firms offering paid employment, thereby giving them economic independence (Mazumdar \& Neetha, 2011). The McKinsey Global Institute report identified the significance of employing more women in the workforce; it would add an additional \$2.9 trillion to India’s annual GDP by 2025 (Woetzel et al., 2015). Therefore, a healthy female Indian workforce is crucial if the country is to benefit from its demographic advantage and sustain its economy. It is imperative that the state healthcare sector in India delivers; it needs to transform itself into a sustainable high performance entity with a reputation for delivering quality breast cancer healthcare underpinned by effective use of social marketing campaigns. Signaling theory (ST) has been found to be valuable for 
describing actions when two parties have access to different types of information (Connelly et al., 2011). For example, the sender may select or signal some information whilst the other party, the receiver, may choose how to interpret the signal. Previous researchers have explored ST in a health policy context to assess the effect of health messages on the signaler (Miech et al., 2015; Simaens \& Koster, 2013). Further, scholars such as Schedler (1999) have argued that within the process of accountability of healthcare providers, trust can be built via a two- way dialogue rather than a one- way transmission of information by signaling that decision makers are interested in the views and well- being of patients. In an emerging country context where ST was used, Mumtaz et al (2013) suggested that in Pakistan where inequities persist, asymmetry in healthcare provision messages were linked to complex patterns of maternal healthcare use. Also, among South African adolescents, exposure to positive and negative signaling communication, when it came to the appropriateness of the use of condoms, was related to existing social norms (Boer \& Mashamba, 2007). Thus, the main objective of this study is to utilize signaling theory:

to identify the unique social, economic and cultural challenges and opportunities faced by health marketers and consumers in raising BCA in an emerging economy such as India.

To accomplish this, the study adopted an interpretative-inductive exploratory methodology alongside a grounded theory approach. Data was collected from key BCA healthcare professionals practicing in the state healthcare sector, the MoHFW and women in India. The participants were experts in cancer care whose experience enabled them to identify the distinctive challenges faced by breast cancer services in an emerging economy context. Further, the specialists were uniquely positioned to pinpoint opportunities for health marketers to produce effective marketing awareness activities because of their professional interactions with those women (consumers) most at risk of breast cancer. Extant medical research and public health literature attest to the value of an individual expert's opinion when 
grouped within a heterogeneous crowd of other experts (Galesic et al., 2015; Mackey \& Bassendowski, 2017). The validity of this approach is supported by Jorm (2015) who suggested that diversity of expertise can produce valuable insights into the phenomena under investigation because the expert's personal experience will enhance and inform the findings. Further, data was gathered from urban working Indian women to produce robust insight from the target group most at risk. The methodological strength of this study is the heterogeneity of expert opinion collected via focus groups that produced in-depth qualitative data addressing the research objective (Krueger \& Casey, 2014; Zikmund et al., 2014). The current study utilizes a grounded theory approach where the data generated, developed and substantiated a theoretical framework via the lens of ST in the context of an emerging economy (Walsh et al., 2015).

In terms of contribution, our study revealed (through an empirical qualitative investigation) and confirmed opportunities as well as complex challenges within BCA at national, state and community levels. The study also identified the negative impact the lack of BCA is having on India's healthcare sector and where social marketing strategies could be leveraged to improve BCA in such an emerging nation. We suggest several ways in which BCA could be effectively managed through health marketers and other relevant stakeholders.

The structure of the paper begins with a discussion of the theoretical grounding of the study followed by a review of extant literature. The research methodology and analysis of results are discussed and presented in a series of tables outlining the challenges and opportunities facing India, as well as health marketers and consumers, in raising BCA. Next, through the lens of ST, the study develops several propositions and advances a conceptual framework which contributes to effective social marketing in an emerging economy. Finally, the limitations of the study are outlined and future research directions discussed. 


\section{India's healthcare sector: an emerging economy context}

Rapid developments in the Indian economy after its liberalization in 1991 have prompted the World Bank to forecast that India will become the world's fourth largest economy by 2020 (Budhwar \& Varma, 2010; Sufaira, 2016). A country of more than one billion people, comprising many cultures, languages and religions, India was predicted in 2016 to surpass China as the fastest growing economy, impacting business operations and practices (Budhwar \& Varma, 2010; Racherla, Huang, \& Liu, 2016). The richness of India's natural resources and plentiful labor force has led many Western firms to internationalize in an attempt to capture the country's rising numbers of middle class consumers (Brosius, 2012; Chen, Chittoor \& Vissa, 2015; Jha \& Singh, 2016). Although public-private partnership (PPP) is emerging to deliver a more holistic healthcare system, the majority of people in India still rely on the state for their primary healthcare.

The right to health is integral to the right to life and therefore the Indian government has a constitutional obligation to provide health facilities. For example, failure of a government hospital to provide a patient with timely medical treatment is in violation of the patient's right to life. Similarly, on several occasions, Indian courts have confirmed the state's obligation to maintain health services more efficiently (Chakraborty \& Chakraborti, 2015). Legally, the Constitution of India incorporates provisions guaranteeing everyone's 'right to the highest attainable standard of physical and mental health' (Constitution of India, 1950). Article 21 of the Constitution guarantees protection of life and personal liberty to every citizen. The Supreme Court of India held the right to live with human dignity (which is enshrined in Article 21 and derives from the principles of state policy), should be extended to the protection of an individual's health (Jain \& Khetrapal, 1950). Recent initiatives in India suggest the government is recognizing its own limitations in women's healthcare and has begun to partner with private players to provide affordable services to the underserved 
(Saxena, 2015). For example, the central government has entered into partnership with notfor-profit non-government organizations (NGOs) such as The Pink Initiative, which seeks to raise awareness about breast cancer via a range of communication channels and events. Literature supports the motive of PPPs to introduce efficiency into developing healthcare systems because it reduces pressure on the public budget, a positive outcome for an emerging economy like India (Mukhopadhyay, 2011). This study identifies the opportunities and challenges that emerge through its emerging economy status to provide effective BCA. ST is applied to examine the state's success in meeting its obligation to provide breast healthcare by exploring its reputation (effectiveness) for delivering quality BCA messages.

\section{Theoretical grounding: Signaling theory}

Signaling theory (ST) is useful for describing behavior when two parties have access to different types of information (Connelly et al., 2011). ST was developed in Spence's (1973) seminal paper in a situation where one firm (the agent, or 'signaler'), conveys some meaningful information about itself (its products or services) to another party (the principal, or 'recipients'). For the purpose of this study, the signaler is India's MoHFW and the recipients of the signals are urban Indian women who are most at risk. Previous research states that to be effective, the signals must be observable, costly to imitate and any false signaling of an over commitment to the consumer result in a loss of credibility (Bruton et al., 2009; Connelly, Ketchen \& Slater, 2011; Lampel \& Shamsie, 2000). Receivers are also important in the signaling cycle. Hence, the sender may select or signal some information whilst the other party, the receiver, may choose how to interpret the signal. The extent to which signaling is effective depends in part on if the receiver vigilantly scans the environment for signals, thus acknowledging a level of capability by the sender (Janney \& Folta, 2006). In this research context, Indian women may be familiar with BCA messages 
from the MoHFW to the extent they are acquainted with methods and processes of how to decipher those messages, i.e. if they have a cellphone, are aware that the MoHFW sends out such messages and actively look for them. Overall, the process signals a level of capability from the sender (MoHFW) of creating a reputation for quality healthcare of its citizens.

Institutional "voids" are permeating organizations in emerging economies and are identifiable by weak infrastructures and an inability to convey their capabilities to stakeholders (Su et al., 2016, p. 479). Through the lens of ST, this study examines the Indian government's ability to create positive signals about the MoHFW's capabilities to manage BCA to all stakeholders. Although Article 38 of the Constitution of India imposes liability on the state to ensure social and economic justice for its citizens, evidence suggests it has failed to improve women's breast cancer healthcare. For example, India's National Cancer Control Program was launched in 1976 but, to date, any large-scale implementation of breast cancer prevention and control strategies have yet to take place and public expenditure remains low (Pramesh et al., 2014). Another key contributory factor to the sustained rate of breast cancer incidence in India is ineffective information from the MoHFW about BCA, resulting in women seeking diagnosis and treatment too late (Mallath et al., 2014). Programmatic experiences in Tamil Nadu, the only state in the country to have scaled-up services for the prevention of common cancers, revealed the need for context specific communication strategies, provision of high quality services, linkages between screening, diagnosis and treatment, and uptake of this evidence by policy-makers and healthcare providers (Krishnan et al., 2013).

Extant literature suggests that ST holds a prominent position in disciplines such as strategic management, entrepreneurship and human resource management. However, its application in this study to health marketing is novel and answers the call for theory development in various areas of management (Boyd et al., 2012; Moss, Neubaum \& 
Meyskens, 2015; Lefebvre, 2012; Wymer, 2011). In any marketplace it is difficult for consumers to know which organizations are genuinely dedicated to the practices they espouse. Often the level of cost invested in the "signal" has a two-fold effect; (i) it reduces information asymmetry and, (ii) highlights the organization's commitment to the cause (Hult, 2011). Thus, in the context of our study, ST involves one marketing organization (the MoHFW) conveying meaningful information about BCA to the consumers (Indian women) in the health marketing arena.

ST is fundamentally concerned with reducing information asymmetry between two parties, striving for perfect information (Spence, 2002; Stiglitz, 2000). Critically, Stiglitz (2000) highlights two potential negative effects of asymmetry information, namely (i) quality (i.e., the reputation of India's MoHFW in matters of breast cancer) and (ii) the receivers' belief in the sender's reputation. It has been argued that the notion of quality shares some characteristics with reputation and prestige and therefore it is pertinent to examine India's MoHFW's ability to deliver these core expectations to reduce asymmetry (Certo, 2003; Kreps \& Wilson, 1982). Using a grounded theory approach, this study proposes that these terms of quality, reputation and prestige are mainly socially constructed and derived from the signaler's perceived quality (or lack thereof). However, efforts to translate such evidence into public health policy and practice in an emerging economy such as India remain dormant and are yet to have an impact in improving cancer awareness, timely diagnosis, treatment access and survival (Chalkidou et al., 2009; Sullivan et al., 2014).

Whilst developing the ST, Spence (1973) utilized the labor market to model the signaling function on the education of a workforce. Further, in Spence's (1973) classic example, the characteristic of quality refers to the underlying, perceived ability of the signaler to fulfill the needs or demands of the receiver. In other words, in this research context, the ability of the signaler to synergize health marketing messages is signaled by a change in 
recipients' behavior due to the MoHFW's breast cancer advertising messages. This notion aligns with prior literature that predicts that the single largest impact on breast cancer in the country will come from raising BCA and educating women about self-examination (Hansa, Kannan, \& Ghosh, 2012). Thus, this study seeks to explore the signaler's efficiency both in overcoming institutional challenges in an emerging economy and in reacting to opportunities to competently deliver effective BCA (Busenitz et al., 2005; Su et al., 2016).

\section{Literature review: challenges facing the healthcare sector of an emerging economy}

This section reviews extant literature and provides a synopsis of the highlights pertaining to the challenges and opportunities for the healthcare sector and health marketers and consumers in an emerging economy such as India.

\section{Challenge 1: India's emerging economy}

The blame for the breast cancer crisis seems to lie with India's economic development producing rapid urbanization while lacking high quality infrastructure for early diagnosis, a situation typical of developing countries (Agarwal et al., 2009). The phenomenal pace of expansion has led to the Westernization of Indian women which essentially means that they start having sex later, have fewer children and breastfeed them less, thus increasing the risk of developing breast cancer over their lifetime (Shetty, 2012). Urban Indian working women also tend to have a more Western diet, leading to obesity which increases the risk of breast cancer (Hansa et al., 2012). Emerging economies such as India also face the challenge of diminishing development aid and donor commitment that impact long-term health improvement within their populations (Sgaier et al., 2013). To date, the Indian government has taken responsibility for managing social marketing programs with various goals (reduce tobacco consumption, promote family planning and encourage breastfeeding), in order to 
improve the nation's health (Culbertson \& Chen, 2013; Deshpande et al., 2013; Murukutla et al., 2011).

In order to improve public health strategy towards women's healthcare in India, the government could build on this recent momentum and initiate social marketing activity to deliver a BCA program. New technology has emerged as an opportunity for health marketers and consumers to support this impetus (Rai, 2016), although, as yet, there is a paucity of literature regarding the effectiveness of mobile technology to communicate health messages in India (see DeSouza et al., 2014; Ramachandran et al., 2013; Shet et al., 2014). The growing economy has enabled a rise in ownership of technology, and mobile phones in particular, by middle class women, the demographic most at risk of breast cancer (Mehta, 2013). The ubiquitous use of mobile technology has already led India's health sector to develop a series of Mobile Health (mHealth) services, offering an obvious opportunity for the MoHFW to build on this reputation to synergize India's BCA messages (Bali \& Singh, 2007; Oliver, 2013; Shet et al., 2010). Ownership by the Indian government to fund and implement early planning of BCA campaigns may be an important strategy to scale up marketing programs to reach those women most at risk and signal a positive trustworthy reputation for India's health sector.

\section{Challenge 2: India's culture and the position of working women}

In India, at least one quarter of all female cancer cases are breast cancer (Breast Cancer India, 2016). Unfortunately, various cultural and religious issues lead to women not accessing health services, being reluctant to consult male doctors, neglecting their own health due to family obligations and generally being over-dependent on other family members to get the required medical help, all of which often results in delay (Deshpande et al., 2013; Murthy, 1982). Social marketing literature challenges health marketers to carefully consider all 
cultural variables when forming a strategy and thus posits a lack of research concerning cancer education (Davis, Buchanan, \& Kyrel, 2013; Massey, Waller, \& Wang, 2013).

\section{Challenge 3: Inconsistency of social marketing theory}

This health marketing study lies within the academic sphere of social marketing which historically has been employed to change individual actions using educational campaigns in an effort to replace unhealthy behavior with positive actions (Friedman et al., 2016; George et al., 2016; Wymer, 2011). An operational definition of 'social marketing' suggests social change management involving the design, implementation and control of programs aimed at increasing the acceptability of a social idea or practice in one or more groups of target adopters (Andreasen, 2002). The definition was extended to include health-related social marketing and focused on an application of integrated marketing concepts and techniques from aligned disciplines to achieve specific behavioral goals, thus improving health and reducing health inequalities (French, Merritt, \& Reynolds, 2011). Since the concept of social marketing evolved, social marketers typically used traditional marketing tools in an attempt to change an individual's behavior, but more recently, researchers have applied interdisciplinary frameworks to develop interventions (Fox \& Kotler, 1980; Helmig \& Thaler, 2010; Luck et al., 2009).

A plethora of conceptual frameworks were devised as early as the 1950s in an effort to explain consumer response behavior to intervention messages; these included the Health Belief Model (Hochbaum, Rosenstock, \& Kegals, 1952), Protection Motivation Theory (Rogers, 1975), Theory of Planned Behavior (Ajzen \& Fishbein, 1980) and Ordered Protection Motivation Schema (Tanner et al., 1991). Many of the frameworks were imported from aligned academic disciplines, suggesting that social marketing is an area of study which is continually re-conceptualizing as a discipline in an effort to obtain greater consumer insight in order to design more effective health messages (Lefebvre, 2012). These 
interdisciplinary frameworks developed from the aligned areas of social science and psychology because researchers concluded that the traditional 4Ps (product, price, place, and promotion) approach to designing health marketing campaigns was no longer a strategic fit for the complexities of contemporary social marketing problems (French et al., 2011; Kelly et al., 2009; Lefebvre, 2012; Michie, Atkins, \& West, 2014; Tapp \& Spotswood, 2013).

Likewise, Crié and Chebat (2013) suggest the need for further exploration of social marketing issues via an interdisciplinary approach. This study responds to these calls by utilizing the ST framework from management theory, thereby extending its scope and contributing to social marketing theory development. We further develop and substantiate the ST framework by utilizing a grounded theory approach.

The synergy between the social sciences has broadened the social marketing discussion about processes and strategies that achieve effective intervention strategies (Domegan et al., 2016; Vlasov \& Mark-Herbert, 2016). Scrutiny of the literature uncovers conflicting academic arguments and no consensus of opinion about what constitutes an effective advertising message. For example, Wymer (2011) suggests the measurement for effectiveness should be the extent to which the social marketing program intervention message persuades individuals to alter their behavior. However, Wallack (1984) posits that campaign success cannot be seen as effective unless institutions at macro level adopt the change in behavior reinforcing the intervention message. However, there does appear to be more agreement that true effectiveness should be measured by the change in behavior at the macro environmental level - such as in government institutions' practices and cultural processes (Cairns \& Stead, 2009; Devos-Comby \& Salovey, 2002; Wymer, 2011). This notion was originally mooted by Smith-McLallen and Fishbein (2008) who proposed that change at macro level should include factors that influence public policy and the wider society, and this has been recently supported by Truong (2016) and Wood (2016). Thus, it is expected that an effective BCA 
strategy in India would impact not only upon its institutional operations but all marketing operational levels (Lefebvre, 2012; Waller \& Fam, 2000; Wymer, 2011). For the purpose of this study, we position macro at central and state levels, meso at industry/organization level and micro at the individual level.

\section{Research design}

The objective of this research is to identify the unique social, economic and cultural challenges and opportunities faced by health marketers and consumers in raising BCA through the application of ST in an emerging context. The examination of the literature in this area suggests that a coherent targeted health marketing campaign would produce increased awareness and reduce the rate of incidence as likely outcomes (Bawa, 2012; Murthy et al., 2007; Shetty, 2012). Thus, to inform any future BCA campaigns, it was important to seek and engage the experience and opinion of breast cancer healthcare experts to help address our research objective. These medical professionals' culturally-determined thought processes, anchored in India's complex historical, religious, ethnic, political, and social influences, were able to provide valuable insight into the study. This research approach aligns with ethnography where the importance placed on the thoughts and opinions the participants give to the issues discussed must be viewed in the context of their experience as practicing breast cancer experts (Hammersley \& Atkinson, 2007). All the experts were active in promoting research in the field of breast cancer with an emphasis on early detection and prevention. The locale chosen for this exploratory approach via focus groups was New Delhi, India, where breast cancer is the most common cancer in women and accounts for $28.6 \%$ of all cancers in women in that geographical area. This region was also selected because it has representation by the signaler in the form of hospitals as well as PPP activities. 
A focus group was chosen for the data-gathering process in Phases 1 and 2 as a means of obtaining multiple opinions on the subject in a flexible and short space of time (Meyer \& Peng, 2015; Zikmund et al., 2014). Focus groups are fortuitous in encouraging serendipitous insights to emerge and, with the guidance of the moderator who has the ability to probe, all ambiguous issues can be explored (Zikmund et al., 2014). The focus group protocol allowed the researchers to scrutinize the respondents' views on the social, economic and cultural challenges and opportunities faced by health marketers and consumers in raising BCA and extrapolate their opinions regarding the efficacy of India's health ministry (signaler) to deliver (signal) quality messages. Finally, the discussion encouraged their thoughts about future strategies and initiatives to communicate BCA to those women most at risk (Krueger \& Casey, 2014). Phase 3 included semi-structured interviews with a sample of women were conducted to capture the consumers' views of BCA in an emerging country.

\subsection{Sample and data collection}

A three-stage process was used by combining a pilot study (Phase 1), a semi-structured focus group (Phase 2), and semi-structured interviews with women as consumers (Phase 3). Both focus groups consisted of a homogeneous range of cultural groups from India with a homogeneous sample of men and women. Further, these consisted of different genders, experiences and age groups as shown in Tables 1a and 1b. In the first phase, an exploratory inquiry was undertaken via two pilot focus groups with two separate healthcare organizations in India. Organization A's main objective is to promote research about the most prevalent cancers in India, including breast cancer, accentuating the benefits of early detection through wellness clinics. This organization also undertakes secondary activities such as training human resource departments and holding workshops for private healthcare workers and NGOs. In total, 16 experts from various breast cancer medical fields were interviewed in a single focus group. Further, four experts were interviewed via a focus group session with 
Organization B, a government-led digital communications department which manages and produces regular health information about BCA for women, accessible by every demographic via mobile and smart devices.

In summary, the major outcomes from the two pilot focus groups were (i) a lack of focused government funding, (ii) poor health marketing awareness by the signaler and (iii) complex cultural challenges preventing health intervention messages reaching those women most at risk. Table 1a provides the composition of participant experts from both organizations. In Phase 2, exploratory data was collected through a focus group with Organization A comprised of 10 (different) expert participants. This sample size compares favorably to other studies and is considered to be highly appropriate, easy to manage and able to achieve research objectives (Krueger \& Casey, 2014; Lindström \& Polsa, 2016).

Participants were Indian cancer care professionals encompassing a diversity of expertise ranging from pathologists and scientists to oncologists and Accredited Social Health Activists (ASHAs). Overall, these experts had practiced between 10 and 32 years (see Table 1b). These information-rich participants were chosen because their position, knowledge, experience, skills or areas of specialization in breast cancer care offered valuable insight into the research objective (Patton, 2002; Usher-Smith et al., 2016). All focus group discussions were conducted in English, audio-recorded and facilitated by the research team using a protocol guide. A semi-structured discussion guide was used mainly to facilitate the topic of interest throughout the discussions and avoid loss of direction. However, given the exploratory nature of this study, the idea was to avoid imposing preconceived frameworks or opinions upon participants, seeking instead to obtain their understanding of the challenges and opportunities within their own frames of reference (Greenwood, Ellmers, \& Holley 2014). Hence, the questions were mostly open-ended and discovery-oriented to facilitate 
open discussions and probing as the research design was inductive and exploratory (Yin, 2014). The discussions lasted about 1.5-2 hours, and were audio-taped and transcribed.

India being a culturally diverse country (Laleman, Pereira \& Malik, 2015; Pereira \& Malik, 2015; 2016), and the subject being culturally sensitive, access to and soliciting answers from individual urban females is challenging. Hence, in consideration of this sensitive issue, the researchers encouraged participation via an indirect email intensive interviewing method as this helped to create a free exchange of information without any social pressure to conform due to the absence of the interviewer (Zikmund et al., 2014). The literature suggests this computer-mediated method enables the researcher to engage in dialogue with isolated, geographically dispersed or marginalized groups similar to the participants in this study (Gibson, 2010; Mann \& Stewart, 2000; McKoyd \& Kerson, 2006). The female participants in Phase 3 were living and working in the same locale as the participants in Phase 1 and 2 of the data collection process which enabled the validation or otherwise of the emerging themes. Prior research highlights the importance of collecting data at various levels of analysis within a common geographical locale to achieve "naturalism" of participants (Paluck \& Cialdini, 2014 p. 82). The participants matched those most commonly diagnosed with breast cancer, aged 30-50 years and educated working women. The data collection process was concluded after information redundancy had been reached at interview 6 and ended at interview 8 (Glaser \& Strauss, 2009). Although Phase 3 involved a heterogeneous collection of professions, a consensus of opinion about the opportunities for and challenges to BCA in India emerged. The characteristics of the women participants are shown in Table 1c.

[Insert Table 1 here] 


\subsection{Data analysis}

In line with the principle of grounded theory, our data led to, generated and substantiated our propositions. Consequently, based on the results, we develop a theoretical framework of ST that seeks to uncover the unique social, economic, cultural and institutional challenges and opportunities faced by both health marketers and consumers of BCA in India. We did not use grounded theory as a lens in isolation or exclusively, but rather used it alongside an interpretive-inductive approach. Data was analyzed in a way that goes beyond mere description, by identifying core categories that then revealed patterns of behavior (both a priori and inductive), resulting in general implications (as propositions). In essence, we used a prescribed 'process' or the 'staples' of grounded theory (see Creswell, 2013; Glaser, 2002; Strauss \& Corbin, 1998). First, we went through a constant process of proposing and checking themes or patterns; second, we maintained that the ST was grounded in our data (and not the other way around); third, we ensured that our data led, generated and substantiated ST (not theory dictating/applied to data); fourth, a theoretical framework was created from data applied more specifically to the context of our study; and fifth, we utilized data from both phases of our study so that it was more grounded in theory. Figure 1 depicts how this process was achieved.

\section{[Insert Figure 1 here]}

Methodologically, we further analyzed the data collected through an interpretiveinductive approach which was employed to understand the 'what and how' nature of the phenomenon (Denzin \& Lincoln, 2000; Remenyi \& Williams, 1998). Through multi-coding, the researchers attempted to identify the unique challenges and opportunities by carefully and comprehensively reviewing the transcripts and exploring the ways by which the healthcare sector attempts to resolve these issues. After transcription, following Strauss and Corbin's (1998) recommendations, data were categorized and integrated to explore key dimensions. To 
obtain a contextualized understanding of the phenomenon being studied, the researchers adopted an iterative research process and tracked back and forth between the literature and transcripts, leading to the emergence of common themes.

Investigator triangulation (via three coders) was used and the interpretations were collated, compared, and examined to warrant consistency of data (Krippendorff, 2004). Given that multiple coders were used, we assessed intercoder reliability using the Krippendorff's alpha test which is considered the most effective standard measure of reliability $(\alpha)$ for qualitative data (Hayes \& Krippendorf, 2007; Hughes \& Garrett, 1990). To accomplish this, we employed a computational procedure (macro) for SPSS called KALPHA developed by Hayes and Krippendorf (2007). Using the nominal data based on each observer's independent rating, we specified 1000 bootstrapping iterations at 95\% confidence intervals (CIs) to compute the reliability estimate and the results revealed a statistically significant moderate degree of reliability $(\alpha=.778)$. This is because the $95 \%$ bootstrap CIs (lower and upper) for all reliability estimates did not contain zero. Any further discrepancies between the coders were resolved through discussions and cross-checking with the interview transcripts (Miles \& Huberman, 1994). Prior research shows that intercoder reliability is important to marketing researchers in part because "high reliability makes it less likely that bad managerial decisions will result from using the data" (Rust \& Cooil, 1994 p. 11). Also, a member checking technique was implemented by sending transcribed data and interpretations back to a sample of participants for them to provide further feedback to enhance accuracy and credibility (Creswell \& Miller, 2000). Lastly, participants' actual words were used and quoted verbatim in the discussion to enhance validity (Denzin \& Lincoln, 2000; Kreutzer et al., 2017).

In his seminal work, Hall (1997) identifies the cumulative effect of themes as a process to understand culture and society. What follows is a review of the findings from the data collection using thematic analysis (Braun, Clarke, \& Terry, 2014; Hsieh \& Shannon, 2005). 
The concluding set of a priori themes (emerging from past literature) is also presented in the results with an attempt to contextualize and explain why they emerge (Hilton et al., 2010). The design of column headings for Tables 2-6 is as follows: in the first column are a priori themes identified from the literature as part of the iterative inductive approach; column two displays the quotes from the literature that supports these $a$ priori themes; columns three and four consist of verbatim quotes from the health experts and women, respectively, that either converge on or diverge from the themes; and, columns five and six reveal the study outcomes as 'opportunities' and 'key challenges', respectively. Finally, as a natural consequence of the analysis process, potential health marketing propositions are presented in column seven. Table 2 presents contemporary academic thought about ST and Table 3 outlines the unique social challenges to BCA and key verbatim quotes from health workers and consumers (women) in India, producing a consensus of emerging themes.

\section{[Insert Tables 2 and 3 here]}

\subsection{Findings}

One unexpected outcome from the focus groups was the range of marketing initiatives mooted by the experts. Closer inspection of the discussion revealed these activities were pertinent to particular marketing levels, including macro-country level, meso-organizational level and micro-individual level (see Table 6). The focus group's suggestions support the social marketing literature's conclusion that the traditional 4Ps approach is obsolete and intervention messages should interact with all stakeholders in the marketing environment (Lefebvre, 2012; Tapp \& Spotswood 2013; Wymer, 2011). For example, participants were asked to rank the best-placed locale to disseminate BCA information on a scale of 1 to 7,1 being the highest. The results show that ASHAs achieved the highest ranking, suggesting they play a critical role in raising BCA. They were identified by the experts as a unique 
marketing force, organized to develop a special relationship at the community level, and with the ability to explain BCA intervention messages and activities because they hold the trust of key family members, including husbands and senior females. However, they are few in number and the resource is stretched. Therefore, until more women are recruited and trained, opportunities for social marketing campaigns could mean designing professional education materials about self-examination for ASHAs to disseminate among schools and workplaces.

The remaining rankings, in order of perceived potential effectiveness, were as follows: schools, media, workplace, celebrities, government and, lastly, places of worship. The fact that places of worship achieved the lowest ranking in a multi-religious and spiritual country suggests that BCA is not efficiently addressed by these macro institutions, producing a void in communication channels. Specifically, one expert mentioned that: "India is a complex country with diverse socio-cultural and religious communities...one message will not be sufficient”. Social marketers should, therefore, be tasked to create and deliver intervention materials adapted for various languages, dialects and religious groups at mid-stream level to inform women seeking guidance from their place of worship. Schools, in second position, were viewed as having significant power to disseminate BCA messages to girls and young women (e.g., Yadav \& Jaroli, 2010). Captured at the early years' stage of education, the experts considered BCA messages at this age would impact greatly on women's health practice. In particular, one participant said:

The government can conduct exhibitions and prepare health education materials and conduct training programs for hospital staff workers at Public Health Centers (PHC) and sub-centers; ASHAs can be trained so they train the population in general .... Education in schools will help not only the children but also the parents and teachers. The media was considered the third most significant channel for disseminating awareness messages: one participant stated “...the media outreach varies with its geography...Internet has traversed less than $30 \%$ of the population while mobile technology has penetrated much 
further”. Celebrities did not achieve a high rank despite the Bollywood industry's immense influence on the population at large. Tables 4 and 5 show extant academic thought about the unique economic and institutional challenges in respect to BCA, and also includes key verbatim quotes from health workers in India, showing converging themes.

\section{[Insert Tables 4 and 5 here]}

In exploring the role played by social marketing in an emerging economy such as India, Table 6 presents contemporary academic thought about the social marketing strategies and key verbatim quotes from health workers in India and the emerging themes.

\section{[Insert Table 6 here]}

The experts were united in their judgements concerning the ability of the healthcare sector to deliver effective BCA messages. "I am not satisfied with the overall management of breast cancer awareness by India's health sector policy," said one, and another, "India's health sector policy is not very effective in raising breast cancer awareness" (see Table 2 for more detail). A conceptual framework developed from the findings of this study illustrates the opportunities and challenges faced by an emerging economy healthcare sector underpinned by social marketing and signaling theory (see Figure 2).

\section{[Insert Figure 2 here]}

Key themes that emerged suggested a lack of focus from the MoHFW as previous national and state campaigns were considered difficult to recall. There was little praise or positive reflection on the central government's approach to women's healthcare. The women participants elaborated in detail about as yet unrealized opportunities at meso level. They highlighted schools, universities and human resource departments in many firms as being soundly placed to provide BCA information and other associated health and well-being 
activities. It was thought that if these multi-stakeholder institutions embraced such practices this could also erode cultural attitudes towards breast cancer being taboo and enable a positive dialogue about the subject between men and women. The women were most vocal about the latter: one said, "In my family we never talk about it ... even among my friends we are too shy... I wouldn't talk to my brother or father about it", while another reiterated that the issue is "rarely discussed between husband and wife ... I would discuss with my mother and I would encourage my daughters to discuss with me". India is still a patriarchal society; even educated professional women do not discuss private matters about their bodies with their husbands, fathers or brothers and therefore it is essential to direct BCA adverting messages to men to increase their awareness of and willingness to discuss the problem. Their interaction and comprehension of BCA appears pivotal in enabling female family members to access medical help at the earliest stage. One positive aspect is that evidence suggests the idea of breast cancer as a cultural taboo is slowly being eroded by female family members willing to discuss the disease with other female relatives. The Pink Initiative in India was identified as a catalyst for such discussions. One participant said, "I have seen the Pink women walk and that's very encouraging for young people like me".

\section{Discussion and conclusions}

Principally, this study sought to identify the unique social, economic and cultural challenges and opportunities faced by health marketers and consumers in raising BCA in an emerging economy such as India through the application of ST. By utilizing a grounded theory approach via three phases of qualitative investigation, the study findings revealed and confirmed complex challenges within BCA at national, state and community levels. The study also identified various negative perceptions surrounding India's healthcare sector where social marketing strategies could be leveraged to improve BCA. As shown in Tables 2-6, 
several propositions are put forward, suggesting ways in which BCA can be effectively managed through health marketers and other relevant stakeholders.

The qualitative results of this study, to an extent, support the notion that the quality of messages (signals) share some characteristics with terms such as reputation and prestige (Certo, 2003; Kreps \& Wilson, 1982). In other words, the experts and urban working Indian women in this research unanimously observed the poor provision of BCA which impacts on the reputation of the Indian government's health policy. At best, the Indian government is recognized (in its capacity as signaler) as having the power to provide BCA but, at worst, the lack of symmetry in messages and resources highlights its inability to fulfill the needs of women and the demands of medical professionals (Connelly et al., 2011). The reason for this appears to lie with the complex cultural challenges of India and the impact of its emerging economy status on demand for services which suggests the lack of a quality characteristic (Spence, 1973). However, India's health sector has an opportunity to improve this element of its reputation by undertaking a holistic and inclusive approach to potential social marketing campaigns (Lefebvre, 2012). Specifically, future BCA should include initial planning, formative research, strategy development, program development, pre-testing, implementation and evaluation (Grier \& Bryant, 2005; Kotler \& Lee, 2008).

Evidence from the findings further reveals that a coherent targeted health marketing campaign for both men and women, with messages tailored to each gender, would produce positive outcomes for both the signaler and urban Indian women (Shetty, 2012). Opportunity exists at stage two of the social marketing process (the development of creative messages for particular segments which are then delivered through the correct marketing mix) for India's health sector to develop key insights about urban Indian women's social and cultural behaviors and to incorporate these to signal positive BCA messages. Prior researchers such as Gupta, Govindarajan, and Malhotra (1999), uncovered the importance of receivers sending 
information back to signalers about the effectiveness of their messages. However, the results from this study suggest this aspect is still fairly elusive in the Indian context. There was some consensus by the participants that ASHAs are best placed to assess if individual women have internalized the message and made a habit of self-examination and therefore marketers could produce effective training materials for ASHAs in line with the propositions identified in Tables 2-6. Further, a marketing opportunity to encourage more educated women to study and qualify as BCA workers is apparent.

Some organizations use costly marketing messages to signal that they are a quality organization and to build trust with their consumers (Hult, 2011). To date, it is clearly evident from all the participants that there has been only a modest investment in BCA by the MoHFW. A sustained BCA program will be a costly initiative for the Indian government to "signal" its commitment to women's health. However, the findings from our study have identified key marketing channels, such as ASHAs and other relevant stakeholders, to deliver effective BCA information. In addition, the results suggest that in order to reduce asymmetry, the MoHFW should ensure that BCA information is made available on a variety of media platforms and produced in a range of dialects as well as being sensitive to gender differences. From a signaling perspective, if the MoHFW embarked on this considerable investment, the signals will be highly observable by Indian women and their families (Connelly, Ketchen \& Slater, 2011). Research has revealed that the success of a signal depends on the extent to which receivers are attuned to looking for it and their willingness to act upon the signal once it is received (Gupta et al., 1999). Receivers who engage in feedback to signals improve the entire signaling process and the cost of investment is justified.

Inconsistent signals, it would appear from this study, are not effective in communicating BCA information to those most at risk. The participants in this research context unanimously agreed that the erratic approach adopted by the MoHFW to raising 
awareness about breast cancer signaled poor commitment and left many women not knowing where to go to seek advice (Janney \& Folta, 2006). Therefore, it could be argued that ST in this Indian health marketing study could be described as having a modelling effect in breast cancer survival rates. If the MoHFW invests in regular signals to communicate their unobservable values in respect of breast cancer and women's well-being, it could legitimize itself to BCA stakeholders such as the participants in this research study, cancer medical professionals and Indian women. Undeniably, this would be a costly marketing exercise, but the expenditure would be justified by women responding positively to BCA messages leading to a reduction in breast cancer mortality rates of the 30-50 age group in the longer term which could not be captured in traditional economic analysis (Khokhar, 2012).

\subsection{Practical implications}

The emerging economy of India has presented women with new-found economic independence and career opportunities (Budhwar, Saini, \& Bhatnagar, 2005). However, the expert participants in this study agree that the lack of BCA campaigns in India's health sector exposes these educated women to some risk. There is an opportunity for human resource departments and university student welfare departments to develop a series of awareness literature, workshops or activities to encourage young women to self-examine as part of a health and well-being strategy sending positive signals to stakeholders and improving the credibility of the source (signaler) (Wilson et al., 2011). The complex cultural issues that operate at all levels of society in India pervade health marketing activities. Findings suggest that women, even when they are contributing economically to the household, are still subject to patriarchal decision-making in matters of health. Also, many women did not tell their fathers, husbands or brothers they were feeling ill because family duties were prioritized over personal health concerns. Substantive awareness about breast cancer could be achieved if health marketers develop educational resources which also target men in an effort to change 
their mindset about women's health. Further, key entities to disseminating awareness information are ASHAs because of their 'social acceptance' by the men of the community. A de-sensitization of the disease would accelerate acceptance at the societal level and alleviate the stigma felt by patients. Traditionally, those who suffer are stigmatized at all levels of society, but an integrated marketing campaign that addresses cultural and language issues could overcome some of these challenges and help reduce the 'fear' element of acknowledging the existence of the disease (Meacham et al., 2016; Shetty, 2012).

Social marketers face considerable challenges in their strategy design to raise BCA and the traditional 4Ps approach, it seems, would be unsuccessful in such an emerging economy (Lefebvre, 2012). Moreover, emerging economy status alone fuses a Western health problem with a weak national health service that is unable to cope effectively with the problem of raising BCA. Encouragingly, however, the benefits of the emerging economy have delivered an improvement in mobile communication technology which could be exploited by social marketers to synergize health messages. Certainly, without a concerted effort by social marketers, breast cancer victims will remain abandoned in an emerging economy such as India.

\subsection{Research limitations and opportunities for future research}

Similar to any research, this study has limitations presenting several opportunities for future research which can be classified in terms of the context, content and methodology. Firstly, this study focuses on a single country and it would be useful if a multi-country comparison was undertaken given the variance in religion, background, cultural, and economic structures within the developing country context (Biggemann \& Fam, 2011). Thus, other emerging markets such as Brazil, South Africa, China and South East Asian countries such as Vietnam and Thailand present as rich contexts for future research. Second, the sample of health experts could be extended to include PPP organizations and women in an effort to 
triangulate data at all marketing levels to ensure generalizability of the results within India, as well as other emerging countries. It should also be noted that the various Indian states are significantly diverse in many aspects, thereby offering future opportunities to examine intrastate comparisons to elicit any variations or similarities.

Third, the findings, propositions and the advanced conceptual framework are grounded in qualitative data collected through focus groups. Although exploratory data via focus groups were deemed most appropriate for the purpose of this study, as well as the nascent state of such research in emerging nations, there is further scope for future research to test the proposed conceptual framework using quantitative data. With quantitative data, larger samples can be used thereby enhancing the generalizability of the findings, which would also help to provide a confirmatory comparative analysis between the Western (developed) perspective and emerging economies. Future research could also involve more homogenous focus groups composed of a greater range of demographic profiles. Lastly, it is anticipated that the findings of this study and application of the conceptual framework will provide a springboard to drive future social marketers to address the weaknesses in current BCA provision among women, not only in India but also other emerging economies. 


\section{References}

Agarwal, G., Ramakant, P., Forgach, E.R.S., Rendón, J.C., Chaparro, J.M., Basurto, C.S., \& Margaritoni, M. (2009). Breast cancer care in developing countries. World Journal of Surgery, 33(10), 2069-2076.

Ajzen, I., \& Fishbein, M. (1980). Understanding attitudes and predicting social behaviour. Englewood Cliffs, NJ: Prentice-Hall.

Andreasen, A.R. (2002). Commercial marketing and social change. Social Marketing Quarterly, 8(2), $41-45$.

Astor, A., Akhtar, T., Matallana, M.A., Muthuswamy, V., Olowu, F.A., Tallo, V., \& Lie, R.K. (2005). Physician migration: views from professionals in Colombia, Nigeria, India, Pakistan and the Philippines. Social Science \& Medicine, 61(12), 2492-2500.

Bali, S., \& Singh, A.J. (2007). Mobile phone consultation for community health care in rural north India. Journal of Telemedecine and Telecare, 13(8), 421-424.

Bawa, R. (2012). Breast cancer in India: current trends and challenges. International Journal of Medical Research Professionals, 1(2), 27-31.

BBC. (2011). India's budget projects economic growth. Retrieved 28 August 2016 from: http://www.bbc.co.uk/news/world-south-asia-12593755.

Berman, P.A. (1998). Rethinking health care systems: private health care provision in India. World Development, 26(8), 1463-1479.

Biggemann, S., \& Fam, K.S. (2011). Business marketing in BRIC countries. Industrial Marketing Management, 40(1), 5-7.

Boer, H., \& Mashamba, M. T. (2007). Gender power imbalance and differential psychosocial correlates of intended condom use among male and female adolescents from Venda, South Africa. British Journal of Health Psychology, 12(1), 51-63.

Boyd, B.K., Haynes, K.T., Hitt, M.A., Bergh, D.D., \& Ketchen, D.J. (2012). Contingency hypotheses in strategic management research. Use, disuse, or misuse? Journal of Management, 38(1), 278313.

Braun, V., Clarke, V., \& Terry, G. (2014). Thematic analysis. Qualitative Research in Clinical Health Psychology, 95-114.

Breast Cancer India. (2016). Trends of breast cancer in India. Retrieved 4 December 2016 from: http://www.breastcancerindia.net/statistics/trends.html.

Brosius, C. (2012). India's middle class: new forms of urban leisure, consumption and prosperity. New Delhi: Routledge.

Bruton, G.D., Chahine, S., \& Filatotchev, I. (2009). Founders, private equity investors, and underpricing in entrepreneurial IPOs. Entrepreneurship Theory and Practice, 33(4), 909-928.

Budhwar, P., \& Varma, A. (2010). Doing Business in India. London: Routledge. 
Budhwar, P.S., Saini, D.S., \& Bhatnagar, J. (2005). Women in management in the new economic environment: The case of India. Asia Pacific Business Review, 11(2), 179-193.

Busenitz, L.W., Fiet, J.O., \& Moesel, D.D. (2005). Signaling in venture capitalist—new venture team funding decisions: does it indicate long-term venture outcomes? Entrepreneurship Theory and Practice 29(1), 1-12.

Cairns, G., \& Stead, M. (2009). Session 5: Nutrition communication obesity and social marketing: works in progress. Proceedings of the Nutrition Society, 68(1), 11-16.

Certo, S.T. (2003). Influencing initial public offering investors with prestige: signaling with board structures. Academy of Management Review, 28(3), 432-446.

Chakraborty, R., \& Chakraborti, C. (2015). India, health inequities, and a fair healthcare provision: a perspective from health capability. Journal of Human Development and Capabilities, 16(4), $567-580$.

Chalkidou, K., Tunis, S., Lopert, R., Rochaix, L., Sawicki, P.T., Nasser, M., and Xerri, B. (2009). Comparative effectiveness research and evidence-based health policy: experience from four countries. Milbank Quarterly, 87(2), 339-367.

Chen, G., Chittoor, R., \& Vissa, B. (2015). Modernizing without westernizing: social structure and economic action in the Indian financial sector. Academy of Management Journal, 58(2), 511537.

Connelly, B.L., Certo, S.T., Ireland, R.D., \& Reutzel, C.R. (2011). Signaling theory: a review and assessment. Journal of Management, 37(1), 39-67.

Connelly, B.L., Ketchen, D.J., \& Slater, S.F. (2011). Toward a "theoretical toolbox" for sustainability research in marketing. Journal of the Academy of Marketing Science, 39(1), 86100 .

Constitution of India (1950). Constitution of India. Retrieved 20 August 2016 from: http://indiacode.nic.in/coiweb/welcome.html.

Creswell, J.W. (2013). Qualitative inquiry and research design: choosing among five approaches. Sage.

Creswell, J.W., \& Miller, D.L. (2000). Determining validity in qualitative inquiry. Theory into Practice, 39(3), 124-130.

Crié, D., \& Chebat, J.C. (2013). Health marketing: toward an integrative perspective. Journal of Business Research, 66(1), 123-126.

Culbertson, H.M., \& Chen, N. (2013). International public relations: a comparative analysis. New York: Routledge.

Davis, J.L., Buchanan, K.L., \& Green, B.L. (2013). Racial/ethnic differences in cancer prevention beliefs: applying the health belief model framework. Health Marketing, 27(6), 384-389.

Denzin, N.K., \& Lincoln, Y.S. (2000). The discipline and practice of qualitative research. Handbook of Qualitative Research, 2, 1-28. 
Deshpande, P.R., Sheriff, M.K., Nazir, A., Bommareddy, S., Tumkur, A., \& Naik, A.N. (2013).

Patient-reported quality of life outcomes in Indian breast cancer patients: importance, review of the researches, determinants and future directions. Journal of Cancer Research and Therapeutics, 9(1), 11-16.

DeSouza, S.I., Rashmi, M.R., Vasanthi, A.P., Joseph, S.M., \& Rodrigues, R. (2014). Mobile phones: the next step towards healthcare delivery in rural India? PloS One, 9(8), e104895.

Devos-Comby, L., \& Salovey, P. (2002). Applying persuasion strategies to alter HIV-relevant thoughts and behavior. Review of General Psychology, 6(3), 287-304.

Domegan, C., McHugh, P., Devaney, M., Duane, S., Hogan, M., Broome, B.J., ... \& Piwowarczyk, J. (2016). Systems-thinking social marketing: conceptual extensions and empirical investigations. Journal of Marketing Management, 32(11/12), 1123-1144.

Fox, K.F., \& Kotler, P. (1980). The marketing of social causes: the first 10 years. Journal of Marketing, 44, 24-33.

French, J., Merritt, R., \& Reynolds, L. (2011). Social marketing casebook. Thousand Oaks: Sage Publications.

Friedman, A.L., Kachur, R.E., Noar, S.M., \& McFarlane, M. (2016). Health communication and social marketing campaigns for sexually transmitted disease prevention and control: what is the evidence of their effectiveness? Sexually Transmitted Diseases, 43(2S), S83-S101.

Galesic, M., Barkoczi, D., Katsikopoulos, K., Perrone, P., Ay, N., Straatman, B., ... \& Madsen, B. (2015). Can small crowds be wise? Moderate-sized groups can outperform large groups and individuals under some task conditions. Santa Fe Institute (SFI) Working paper: 2015-12-051.

Gangane, N., Manvatkar, S., Ng, N., Hurtig, A.K., \& San Sebastián, M. (2016). Prevalence and risk factors for patient delay among women with breast cancer in rural India. Asia-Pacific Journal of Public Health, 28(1), 72-82.

George, K. S., Roberts, C. B., Beasley, S., Fox, M., \& Rashied-Henry, K. (2016). Our health is in our hands a social marketing campaign to combat obesity and diabetes. American Journal of Health Promotion, 30(4), 283-286.

Gibson, L. (2010). Using email interviews. Retrieved 26 February 2017 from: http://eprints.ncrm.ac.uk/1303/

Glaser, B.G. (2002). Conceptualization: on theory and theorizing using grounded theory. International Journal of Qualitative Methods, 1(2), 23-38.

Glaser, B.G., \& Strauss, A.L. (2009). The discovery of grounded theory: Strategies for qualitative research. New York: Transaction Publishers.

Greenwood, N., Ellmers, T., \& Holley, J. (2014). The influence of ethnic group composition on focus group discussions. BMC Medical Research Methodology, 14(107), 1-13.

Grier, S., \& Bryant, C.A. (2005). Social marketing in public health. Annual Review of Public Health, 26, 319-339. 
Gupta, A.K., Govindarajan, V., \& Malhotra, A. (1999). Feedback-seeking behavior within multinational corporations. Strategic Management Journal, 20(3), 205-222.

Hall, S. (1997). Representation: cultural representations and signifying practices (Vol. 2). London: Sage Publications.

Hammersley, M., \& Atkinson, P. (2007). Ethnography: principles in practice. London: Routledge.

Hansa, J., Kannan, R., \& Ghosh, S.K. (2012). Screening of 185DelAG, 1014DelGT and 3889DelAG BRCA1 mutations in breast cancer patients from North-East India. Asian Pacific Journal of Cancer Prevention, 13(11), 5871-5874.

Hayes, A. F., \& Krippendorff, K. (2007). Answering the call for a standard reliability measure for coding data. Communication Methods and Measures, 1(1), 77-89.

Helmig, B., \& Thaler, J. (2010). On the effectiveness of social marketing — what do we really know? Journal of Nonprofit and Public Sector Marketing, 22(4), 264-287.

Hilton, S., Hunt, K., Langan, M., Bedford, H., \& Petticrew, M. (2010). Newsprint media representations of the introduction of the HPV vaccination programme for cervical cancer prevention in the UK (2005-2008). Social Science and Medicine, 70(6), 942-950.

Hochbaum, G., Rosenstock, I., \& Kegels, S. (1952). Health belief model. United States Public Health Service. Retrieved 4 December 2016 from: http://www.infosihat.gov.my/ infosihat/artikelHP/bahanrujukan/HE_DAN_TEORI/DOC/Health\%20Belief\% 20Model.doc.

Hsieh, H.F., \& Shannon, S.E. (2005). Three approaches to qualitative content analysis. Qualitative Health Research, 15(9), 1277-1288.

Hughes, M. A., \& Garrett, D. E. (1990). Intercoder reliability estimation approaches in marketing: a generalizability theory framework for quantitative data. Journal of Marketing Research, 27(2), 185-195.

Hult, G.T.M. (2011). Market-focused sustainability: market orientation plus! Journal of the Academy of Marketing Science, 39, 1-6.

Jain, M., \& Khetrapal, B.S. (1950). The Constitution of India. Central Law Agency.

Janney, J.J., \& Folta, T.B. (2006). Moderating effects of investor experience on the signaling value of private equity placements. Journal of Business Venturing, 21(1), 27-44.

Jha, B.K., \& Singh, B.J.R. (2016). Corporate social responsibility in India. International Journal of Higher Education Research \& Development, 1(1), 1-8.

Jorm, A.F. (2015). Using the Delphi expert consensus method in mental health research. Australian and New Zealand Journal of Psychiatry, 49, 887-897.

Kalra, A. (2016). India's health budget may rise after minister warns of funding crunch. Retrieved 22 March 2017 from: http://uk.reuters.com/article/us-india-budget-health-exclusiveidUKKBN15E1MB 
Kelly, M.P., Stewart, E., Morgan, A., Killoran, A., Fischer, A., Threlfall, A., \& Bonnefoy, J. (2009). A conceptual framework for public health: NICE's emerging approach. Public Health, 123(1), e14-e20.

Khokhar, A. (2012). Breast cancer in India: where do we stand and where do we go? Asian Pacific Journal of Cancer Prevention, 13(10), 4861-4866.

Kotler, P., \& Lee, N. (2008). Corporate social responsibility: doing the most good for your company and your cause. New York: John Wiley and Sons.

Kreps, D.M., \& Wilson, R. (1982). Reputation and imperfect information. Journal of Economic Theory, 27(2), 253-279.

Kreutzer, L., Dahlke, A.R., Love, R., Ban, K.A., Yang, A.D., Bilimoria, K.Y., \& Johnson, J.K. (2017). Exploring qualitative perspectives on surgical resident training, well-being, and patient care. Journal of the American College of Surgeons, 224(2), 149-159.

Krippendorff, K. (2004). Measuring the reliability of qualitative text analysis data. Quality and Quantity, 38(6), 787-800.

Krishnan, S., Madsen, E., Porterfield, D., \& Varghese, B. (2013). Advancing cervical cancer prevention in India: implementation science priorities. The Oncologist, 18(12), 1285-1297.

Krueger, R.A., \& Casey, M.A. (2014). Focus groups: a practical guide for applied research. New Delhi: Sage publications.

Laleman, F., Pereira, V., \& Malik, A. (2015). Understanding cultural singularities of 'Indianness' in an intercultural business setting. Culture and Organization, 21(5), 427-447.

Lampel, J., \& Shamsie, J. (2000). Critical push: Strategies for creating momentum in the motion picture industry. Journal of Management, 26(2), 233-257.

Lefebvre, R.C. (2012). Transformative social marketing: co-creating the social marketing discipline and brand. Journal of Social Marketing, 2(2), 130-137.

Lindström, T., \& Polsa, P. (2016). Coopetition close to the customer - a case study of a small business network. Industrial Marketing Management, 53, 207-215.

Luck, J., Hagigi, F., Parker, L., Yano, E., Rubenstein, L., \& Kirchner, J. (2009). A social marketing approach to implementing evidence-based practice in VHA QUERI: the TIDES depression collaborative care model. Implementation Science, 4(64), 1-12.

Mackey, A., \& Bassendowski, S. (2017). The history of evidence-based practice in nursing education and practice. Journal of Professional Nursing, 33(1), 51-55.

Mallath, M.K., Taylor, D.G., Badwe, R.A., Rath, G.K., Shanta, V., Pramesh, C.S., ... \& Kapoor, S. (2014). The growing burden of cancer in India: epidemiology and social context. The Lancet Oncology, 15(6), e205-e212.

Mann, C., \& Stewart, F. (2000). Internet communication and qualitative research: a handbook for research online. London: Sage Publications Ltd. 
Martinez, J., \& Martineau, T. (1998). Rethinking human resources: an agenda for the millennium, Health Policy and Planning, 13(4), 345-358.

Massey, G.R., Waller, D.S., Wang, P.Z., \& Lanasier, E.V. (2013). Marketing to different Asian communities: the importance of culture for framing advertising messages, and for purchase intent. Asia Pacific Journal of Marketing and Logistics, 25(1), 8-33.

Mazumdar, I., \& Neetha, N. (2011). Gender dimensions: employment trends in India, 1993-94 to 2009-10. Economic \& Political Weekly, 46(43), 118-26.

McCoyd, J.L., \& Kerson, T.S. (2006). Conducting intensive interviews using email: a serendipitous comparative opportunity. Qualitative Social Work, 5(3), 389-406.

Meacham, E., Orem, J., Nakigudde, G., Zujewski, J.A., \& Rao, D. (2016). Exploring stigma as a barrier to cancer service engagement with breast cancer survivors in Kampala, Uganda. PsychoOncology, 25(10), 1206-1211.

Mehta, B.S. (2013). Capabilities, costs, networks and innovations: impact of mobile phones in rural India. Institute for Human Development Working Paper 29. New Delhi: Institute for Human Development.

Meyer, K.E., \& Peng, M.W. (2015). Theoretical foundations of emerging economy business research. Journal of International Business Studies, 47(1), 3-22.

Michie, S., Atkins, L., \& West, R. (2014). The behaviour change wheel: a guide to designing interventions. Great Britain: Silverback Publishing.

Miech, R.A., Johnston, L., O’Malley, P.M., Bachman, J.G., Schulenberg, J., \& Patrick, M E. (2015). Trends in use of marijuana and attitudes toward marijuana among youth before and after decriminalization: The case of California 2007-2013. International Journal of Drug Policy, 26(4), 336-344.

Miles, M.B., \& Huberman, A.M. (1994). Qualitative data analysis: an expanded sourcebook. London: Sage Publications.

Moss, T.W., Neubaum, D.O., \& Meyskens, M. (2015). The effect of virtuous and entrepreneurial orientations on microfinance lending and repayment: a signaling theory perspective. Entrepreneurship Theory and Practice, 39(1), 27-52.

Mukhopadhyay, C. (2011). Are private investments serving the poor in India? Journal of Infrastructure Development, 3(1), 39-63.

Mumtaz, Z., Levay, A., Bhatti, A., \& Salway, S. (2013). Signalling, status and inequities in maternal healthcare use in Punjab, Pakistan. Social Science \& Medicine, 94, 98-105.

Murthy, N. (1982). Reluctant patients-the women of India. World Health Forum, 3(3), 315-316.

Murthy, N.S., Agarwal, U.K., Chaudhry, K., \& Saxena, S. (2007). A study on time trends in incidence of breast cancer - Indian scenario. European Journal of Cancer Care, 16(2), 185-186. 
Murukutla, N., Turk, T., Prasad, C.V.S., Saradhi, R., Kaur, J., Gupta, S., ... \& Wakefield, M. (2011). Results of a national mass media campaign in India to warn against the dangers of smokeless tobacco consumption. Tobacco Control, 21(1), 12-17.

NASSCOM. (2010). The IT-BPO sector in India: strategic review 2010. NASSCOM, New Delhi.

O’Donnell, O., Van Doorslaer, E., Rannan-Eliya, R.P., Somanathan, A., Adhikari, S.R., Akkazieva, B., ... \& Huq, M.N. (2008). Who pays for health care in Asia? Journal of Health Economics, $27(2), 460-475$.

Oliver, N. (2013). Effectiveness of mobile phone messaging in prevention of type 2 diabetes by lifestyle modification in men in India: a prospective, parallel-group, randomised controlled trial. The Lancet Diabetes and Endocrinology, 1(3), 191-198.

Paluck, E.L., \& Cialdini, R.B. (2014). Field research methods. In H. T. Reis, \& Judd, C. M. (Ed.), Handbook of research methods in social and personality psychology (pp. 81-97). New York: Cambridge University Press.

Patton, M.Q. (2002). Qualitative research and evaluation methods. Thousand Oaks, CA: Sage Publications.

Pereira, V., \& Malik, A. (2015). Culture in Indian organisations: evidence-based research and practice. In V. Pereira \& A. Malik (Eds.), Investigating cultural aspects in Indian organizations: empirical evidence (pp. 1-10). Cham: Springer International Publishing.

Pereira, V., \& Malik, A. (2016). Conclusion and future research directions. In Ashish Malik \& Vijay Pereira (Eds). Indian Culture and Work Organisations in Transition (pp. 1-13). New Delhi India: Routledge, Taylor \& Francis Group.

Pramesh, C.S., Badwe, R.A., Borthakur, B.B., Chandra, M., Raj, E.H., Kannan, T., ... \& Rath, G.K. (2014). Delivery of affordable and equitable cancer care in India. The Lancet Oncology, 15(6), e223-e233.

Racherla, U.S., Huang, K.G.L., \& Liu, K.C. (2016). Introduction: China and India as contrast pair in innovation and IP. In K.C. Liu \& U.S. Racherla (Eds.), Innovation and IPRs in China and India: myths, realities and opportunities (pp. 3-24). Singapore: Springer.

Rai, S. (2016). India just crossed 1 billion mobile subscribers milestone and the excitement's just beginning. Retrieved 12 October 2016 from: http://www.forbes.com/sites/saritharai/2016/01/06/india-just-crossed-1-billion-mobilesubscribers-milestone-and-the-excitements-just-beginning/\#4b25c76b5ac2.

Ramachandran, A., Snehalatha, C., Ram, J., Selvam, S., Simon, M., Nanditha, A., ... Rath, G.K., \& Gandhi, A.K. (2014). National cancer control and registration program in India. Indian Journal of Medical and Paediatric Oncology, 35(4), 288-290.

Rath, G. K., \& Gandhi, A. K. (2014). National cancer control and registration program in India. Indian Journal of Medical and Paediatric Oncology, 35(4), 288-290. 
Remenyi, D., \& Williams, B. (1998). Doing research in business and management: an introduction to process and method. London: Sage Publications.

Rogers, R.W. (1975). A protection motivation theory of fear appeals and attitude change. The Journal of Psychology, 91(1), 93-114.

Rust, R., \& Cooil, B. (1994). Reliability measures for qualitative data: theory and implications. Journal of Marketing Research, 31(1), 1-14.

Saxena, N. (2015). Public-private partnership in healthcare in India: analysis of success factor using quantitative content analysis. Retrieved 5 December 2016 from: http://vslir.iima.ac.in/xmlui/handle/11718/14115.

Schedler, A. (1999). The self-restraining state: power and accountability in new democracies. Colorado, US: Lynne Rienner Publishers.

Sengupta, A., \& Nundy, S. (2005). The private health sector in India. British Medical Journal 331, $1157-1158$.

Sgaier, S.K., Ramakrishnan, A., Dhingra, N., Wadhwani, A., Alexander, A., Bennett, S., ... \& Piot, P.K. (2013). How the Avahan HIV prevention program transitioned from the Gates Foundation to the government of India. Health Affairs, 32(7), 1265-1273.

Shet, A., Arumugam, K., Rodrigues, R., Rajagopalan, N., Shubha, K., et al. (2010). Designing a mobile phone-based intervention to promote adherence to antiretroviral therapy in South India. AIDS and Behavior, 14(3), 716-720.

Shet, A., De Costa, A., Kumarasamy, N., Rodrigues, R., Rewari, B.B., Ashorn, P., ... \& Diwan, V. (2014). Effect of mobile telephone reminders on treatment outcome in HIV: evidence from a randomised controlled trial in India. British Medical Journal, 349, g5978.

Shetty, P. (2012). India faces growing breast cancer epidemic. The Lancet, 379(9820), 992-993.

Simaens, A., \& Koster, M. (2013). Reporting on sustainable operations by third sector organizations: A signalling approach. Public Management Review, 15(7), 1040-1062.

Smith-McLallen, A., \& Fishbein, M. (2008). Predictors of intentions to perform six cancer-related behaviours: roles for injunctive and descriptive norms. Psychology, Health and Medicine, 13(4), $389-401$.

Spence, M. (1973). Job market signaling. The Quarterly Journal of Economics, 87(3), 355-374.

Spence, M. (2002). Signaling in retrospect and the informational structure of markets. The American Economic Review, 92(3), 434-459.

Stiglitz, J.E. (2000). The contributions of the economics of information to twentieth century economics. Quarterly Journal of Economics, 115, 1441-1478.

Strauss, A., \& Corbin, J. (1998). Basics of qualitative research: techniques and procedures for developing grounded theory. Thousand Oaks, CA: Sage Publications, Inc.

Su, W., Peng, M.W., Tan, W., \& Cheung, Y.L. (2016). The signaling effect of corporate social responsibility in emerging economies. Journal of Business Ethics, 134(3), 479-491. 
Sufaira, C. (2016). Growth and diversification of manufacturing export in India since 1991. Journal of International Economics, 6(2), 111-123.

Sullivan, R., Badwe, R.A., Rath, G.K., Pramesh, C. S., Shanta, V., Digumarti, R., . . Purushotham, A.D. (2014). Cancer research in India: national priorities, global results. The Lancet Oncology, 15(6), e213-e222.

Tanner Jr, J.F., Hunt, J.B., \& Eppright, D.R. (1991). The protection motivation model: a normative model of fear appeals. Journal of Marketing, 55(3), 36-45.

Tapp, A., \& Spotswood, F. (2013). From the 4Ps to COM-SM: reconfiguring the social marketing mix. Journal of Social Marketing, 3(3), 206-222.

Truong, V.D. (2016). Government-led macro-social marketing programs in Vietnam outcomes, challenges, and implications. Journal of Macromarketing, doi: 10.1177/0276146716660833.

Usher-Smith, J.A., Silarova, B., Ward, A., Youell, J., Muir, K.R., Campbell, J., \& Warcaba, J. (2016). Incorporating cancer risk information into general practice: a qualitative study using focus groups with healthcare professionals. The British Journal of General Practice, doi: 10.17863/CAM.6066.

Vlasov, M., \& Mark-Herbert, C. (2016). Enabling behaviour change - social practice theory perspective on social marketing strategy. In 4th Nordic Conference on Consumer Research. Retrieved 4 December 2016 from: http://www.divaportal.org/smash/record.jsf?pid=diva2\%3A929994\&dswid=4272.

Vujicic, M., Zurn, P., Diallo, K., Adams, O., \& Dal Poz, M.R. (2004). The role of wages in the migration of health care professionals from developing countries. Human Resources for Health, 2(3), 1-14.

Wallack, L. (1984). Social marketing as prevention: uncovering some critical assumptions. Advances in Consumer Research, 11(1), 682-687.

Waller, D.S., \& Fam, S.K. (2000). Cultural values and advertising in Malaysia: views from the industry. Asia Pacific Journal of Marketing and Logistics, 12(1), 3-16.

Walsh, I., Holton, J.A., Bailyn, L., Fernandez, W., Levina, N., \& Glaser, B. (2015). What grounded theory is... a critically reflective conversation among scholars. Organizational Research Methods, 18(4), 581-599.

Wilson, S.J., Tanner-Smith, E.E., Lipsey, M.W., Steinka-Fry, K., \& Morrison, J. (2011). Dropout prevention and intervention programs: effects on school completion and dropout among schoolaged children and youth. Campbell Systematic Reviews, 8, 1-62.

Woetzel, J., Madgavkar, A., Ellingrud, K., Labaye, E., Devillard, S., Kutcher, E., Manyika, J., Dobbs, R., \& Krishnan, M. (2015). The power of parity: How advancing women's equality can add $\$ 12$ trillion to global growth, McKinsey Global Institute Report. Retrieved 20 August 2016 from: http://www.mckinsey.com/globalthemes/employment-and-growth/how-advancingwomensequality-can-add-12-trillion-to-globalgrowth. 
Wood, M. (2016). Social marketing for social change. Social Marketing Quarterly, 22(2), 107-118.

Wymer, W. (2011). Developing more effective social marketing strategies. Journal of Social Marketing, 1(1), 17-31.

Yadav, P., \& Jaroli, D.P. (2010). Breast cancer: awareness and risk factors in college-going younger age group women in Rajasthan. Asian Pacific Journal of Cancer Prevention, 11(2), 319-22.

Yin, R.K. (2014). Case study research, design and methods, $5^{\text {th }}$ Ed. Thousand Oaks: SAGE Publications.

Zikmund, W.G., Ward, S., Winzar, H., Lowe, B., \& Babin, B.J. (2014). Marketing Research: 3rd Asia Pacific Edition. Melbourne: Cengage Learning. 